Article

\title{
Perpendicular Structure Formation of Block Copolymer Thin Films during Thermal Solvent Vapor Annealing: Solvent and Thickness Effects
}

\author{
Qiuyan Yang (1) and Katja Loos* \\ Macromolecular Chemistry \& New Polymeric Materials, Zernike Institute for Advanced Materials, \\ University of Groningen, Nijenborgh 4, 9747 AG Groningen, The Netherlands; yangqiuxiaoyan@163.com \\ * Correspondence: k.u.loos@rug.nl; Tel.: +31-050-363-6867
}

Received: 25 September 2017; Accepted: 13 October 2017; Published: 18 October 2017

\begin{abstract}
Solvent vapor annealing of block copolymer (BCP) thin films can produce a range of interesting morphologies, especially when the perpendicular orientation of micro-domains with respect to the substrate plays a role. This, for instance, allows BCP thin films to serve as useful templates for nanolithography and hybrid materials preparation. However, precise control of the arising morphologies is essential, but in most cases difficult to achieve. In this work, we investigated the solvent and thickness effects on the morphology of poly(styrene- $b-2$ vinyl pyridine) (PS-b-P2VP) thin films with a film thickness range from $0.4 L_{0}$ up to $0.8 L_{0}$. Ordered perpendicular structures were achieved. One of the main merits of our work is that the phase behavior of the ultra-high molecular weight BCP thin films, which hold a 100-nm sized domain distance, can be easily monitored via current available techniques, such as scanning electron microscope (SEM), atomic force microscope (AFM), and transmission electron microscope (TEM). Systematic monitoring of the self-assembly behavior during solvent vapor annealing can thus provide an experimental guideline for the optimization of processing conditions of related BCP films systems.
\end{abstract}

Keywords: block copolymers; thin films; annealing; selectivity; lamellar

\section{Introduction}

The self-assembly of block copolymer (BCP) thin films can generate structures with a tailored length, enabling them to be desirable templates for nano-manufacturing [1]. Controlling the morphology of ordered BCPs was normally achieved via thermal annealing or solvent vapor annealing (SVA) [2,3]. In SVA, as-prepared block polymer thin films are exposed to vapors of one or more solvents at temperatures typically well below the bulk $T_{\mathrm{g}}$ of both blocks to form a swollen and mobile polymer film on the substrate [4]. This process is highly effective over comparatively short timescales, particularly for high molecular weight BCPs in comparison to thermal annealing, due to the dramatic enhancements of chain mobility afforded by the presence of a plasticizing solvent in the BCP film as compared to the thermal-activation of chain motion in a dry melt [1]. Such rapid assembly kinetics in SVA and the versatility of the technique motivate great efforts in this area. Among reported BCPs thin films, the self-assembly of poly(styrene- $b$-vinyl pyridine) (PS- $b$-PVP) films under SVA was particularly studied because of the intrinsically high Flory-Huggins segmental interaction parameter $(\chi)$ for phase separation and the functionality of the vinylpyridine group with small molecules and nanoparticles for the further fabrication of hybrid materials. For example, various arrays including micellar, laminar, and cylindrical domains of PS- $b$-P4VP with a high degree of orders were produced by Park and Russell, which were further used as the templates for the fabrication of porous films [5], dot and stripe arrays [6,7], metallic line patterns [8], and ordered structure designs [9-11]. 
However, SVA is a more complex process than thermal annealing. The morphology in this process not only depends on the intrinsic properties of $\mathrm{BCP}$, such as the extent of $\chi$, the degree of polymerization $(N)$, and the composition (block ratio $f$ ), but also on type of the solvent [12-19] and the film thickness [20-22]. Generally, preferentially wetting of one block at the substrate surface or free surface on the contrary induces preferential parallel orientation of domains [22]. For example, Hasegawa et al. showed that the use of nonselective tetrahydrofuran (THF), selective solvent acetone for P2VP domain, or selective solvent toluene for the PS domain in the annealing of thin films PS- $b$-P2VP could cause the BCP to form significantly different morphologies, further asserting that various perpendicular structures can be formed predominantly on the substrates with the proper choice of solvent $[23,24]$. In addition to the interfacial interaction greatly influenced by the solvent vapor in SVA systems, the thickness of BCP films also affects the orientation of domains [20-22,25]. Chang et al. investigated the phase behaviors of polystyrene-block-polyisoprene (PS- $b$-PI) thin films and constructed a phase diagram as a function of film thickness over the range of 150-2410 nm (7-107 $L_{0}\left(L_{0}\right.$ : domain spacing)) and temperature. In the presence of solvent vapor, commensurability between the swelled film thickness and $L_{0}$ is found to be essential to produce a well-ordered self-assembled morphology [26].

Despite the great progress made on the control of the morphology of $\mathrm{BCP}$ during the past decades and the more comprehensive understanding of SVA process that is established, a small change on one parameter normally requires corresponding adjustments on other conditions to maintain the morphology, because self-assembly through SVA process is actually a systematic work based on many multivariate factors. Current controlling data in this area are already abundant but still far from sufficient to build up an integrated handbook to guide the structural formation of $\mathrm{BCP}$ thin films. Systematic investigations on the phase behavior of $\mathrm{BCP}$ are still required in some cases, for example, BCPs with high molecular weight are not yet well reported. Even though BCPs with an ultra-small period have received the most attention for nanolithography, self-assembled structures from high molecular weight BCPs hold feature sizes above a hundred on the nanometer scale and are also in demand for applications such as photonic crystals, solar cells, and desalination membranes [26].

Here, the self-assembly behaviors of high molecular weight poly(styrene- $b-2$ vinyl pyridine) (PS- $b$-P2VP) BCP with $M_{\mathrm{n}}(\mathrm{PS})=133 \mathrm{~kg} \mathrm{~mol}^{-1}, M_{\mathrm{n}}(\mathrm{P} 2 \mathrm{VP})=132 \mathrm{~kg} \mathrm{~mol}^{-1}\left(f_{\mathrm{ps}} \approx 0.5\right)$, and $M_{\mathrm{W}} / M_{\mathrm{n}}=1.15$ during the SVA process are monitored in a detail. A thickness range of $0.4 L_{0}$ to $0.8 L_{0}$ (i.e., from $60 \mathrm{~nm}$ to $100 \mathrm{~nm}$ ) avoiding extra layer formation on the top of thin films was specifically studied here to achieve the perpendicular structures of PS- $b$-P2VP. With the aim of fabricating ordered and reproducible BCP structures in a controllable way, a series of systematic studies on the SVA produced morphologies as functions of solvent type, temperature, film thickness, and annealing time were investigated.

\section{Materials and Methods}

\subsection{Materials}

PS- $b$-P2VP was purchased from Polymer Source, Inc. and used as received: P5742-S2VP, $M_{\mathrm{n}}(\mathrm{PS})=133 \mathrm{~kg} \mathrm{~mol}^{-1}, M_{\mathrm{n}}(\mathrm{P} 2 \mathrm{VP})=132 \mathrm{~kg} \mathrm{~mol}^{-1}, M_{\mathrm{w}} / M_{\mathrm{n}}=1.15$. Toluene Biosolve Chemicals (Biosolve BV, Valkenswaard, The Netherlands), >99.7\%) and chloroform (Biosolve Chemicals, $>99.9 \%$ ) were used as received Silicon substrates (Prime CZ-Si wafer, thickness $=625 \pm 20 \mu \mathrm{m}$, (100), 1-sidepolished, p-type (Boron) TTV $<10 \mu \mathrm{m}, 15-25 \mathrm{Ohm}$ ) were supplied by Micro Chemicals $\mathrm{GmbH}$, Ulm, Germany.

\subsection{Preparation of $P S-b-P 2 V P$ Thin Films}

PS- $b$-P2VP thin films were prepared by spin-coating of the polymer solution onto $1 \mathrm{~cm} \times 1 \mathrm{~cm}$ silicon wafer. Silicon (Si) substrates of $1 \mathrm{~cm}^{2}$ with a native silicon oxide layer on the surface were ultrasonically cleaned in water, ethanol, and acetone for $10 \mathrm{~min}$ (three times for each type of solvent), 
respectively, and dried under a stream of air gas before use. The concentration of the polymer in solution and also the spin-coating speed were adjusted with a couple of trial experiments to yield films with the desired thickness and different morphologies, as shown in Table 1.

Table 1. Spin-coating conditions for various PS- $b$-P2VP films with different thicknesses.

\begin{tabular}{cccc}
\hline Solvent & Concentration $(w / v)$ & Spin-Coating Speed $(\mathbf{r p m})$ & Film Thickness $(\mathbf{n m})$ \\
\hline \multirow{3}{*}{ Toluene } & 1.5 & 3000 & $\sim 60$ \\
& 1.5 & 2500 & $\sim 80$ \\
& 1.5 & 2000 & $\sim 85$ \\
2.0 & 3000 & $\sim 100$ \\
& 2.0 & 2000 & $\sim 120$ \\
\hline
\end{tabular}

The obtained films were dried under vacuum to remove the retained solvent before further solvent vapor annealing, especially when different solvent vapors were applied for annealing. However, the as-spin-coated sample was directly used for solvent vapor annealing if the solvent vapor was the same as that of the casting solvent. SVA treatments were conducted in a $60-\mathrm{mL}$ glass container filled with solvent vapors by placing the spin-coated films at the bottom. One open small 4-mL bottle, which was typically filled with $2 \mathrm{~mL}$ of solvent, was placed inside this container to yield the solvent vapor. By closing the lid of the container and putting it inside a chamber with proper temperature control, the relative solvent vapor pressure inside the dish could roughly be adjusted, resulting in the swelling of the films to different swelling ratios. Solvent vapor annealing was conducted in chloroform at $27^{\circ} \mathrm{C}$ and in toluene at temperatures from 50 to $80^{\circ} \mathrm{C}$ with various annealing times with the aim of obtaining ordered morphologies of block copolymers.

Thin films of PS- $b$-P2VP prepared by spin-coating were floated off of the silicon substrates by immersing the samples in a $1 \mathrm{wt} \% \mathrm{NaOH}$ aqueous solution for half an hour, after which they were dried on copper grids for TEM imaging.

\subsection{Characterization}

Atomic Force Microscopy (AFM) measurements were carried out on a Digital Instruments Enviro Scope AFM equipped with a Nanoscope III controller in tapping mode using Veeco RTESPW silicon cantilevers $\left(f_{0}=240-296 \mathrm{kHz}\right.$ and $k=20-80 \mathrm{~N} \mathrm{~m}^{-1}$ as specified by the manufacturer). AFM images were typically obtained with a scan range of 10 and $3 \mu \mathrm{m}^{2}$ and a frequency of $0.5 \mathrm{~Hz} /$ line. Film thicknesses were measured by scratching the film in three different places with a razor blade followed by scanning across the scratch edges. In this case, the aspect ratio was 1:8 to minimize distortion along the slow scanning axis due to thermal drift. Transmission electron microscopy (TEM) was carried out on a Philips CM12 transmission electron microscope (Philips, Amsterdam, The Netherlands) operating at an accelerating voltage of $120 \mathrm{kV}$. TEM images were recorded on a Gatan slow-scan charge-coupled-device (CCD) camera.

\section{Results and Discussion}

A PS- $b$-P2VP BCP with a molecular weight $M_{\mathrm{n}}(\mathrm{PS})=133,000 \mathrm{~g} \mathrm{~mol}^{-1}, \mathrm{M}_{\mathrm{n}}(\mathrm{P} 2 \mathrm{VP})=132,000 \mathrm{~g} \mathrm{~mol}^{-1}$ $\left(f_{\mathrm{ps}} \approx 0.5\right)$, and $M_{\mathrm{w}} / M_{\mathrm{n}}=1.15$ is chosen. Contributed by its high $\chi N(\geq 100)$ value, a lamellar spacing $\left(L_{0}\right)$ around $146 \mathrm{~nm}$ is observed in the TEM image of an annealed BCP sample with a thickness higher than $45 L_{0}$ (Figure 1). The PS- $b$-P2VP copolymer exists as spherical micelles (with a PS corona and a P2VP core) in toluene solutions due to the favorable interaction with the PS domains [27-30] and is normally shown as milk white in color in the solutions. On the contrary, in the presence of chloroform, PS-b-P2VP solution is absolutely transparent as observed by eye, even at a high concentration of $2.0 \mathrm{wt} \%$, suggesting the better solubility of PS- $b$-P2VP in chloroform than in toluene, which can be easily explained by the Hildebrand solubility parameters, as shown in Table 2 . 


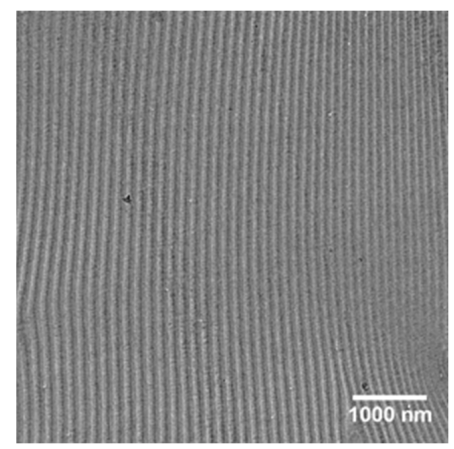

Figure 1. TEM image of the PS- $b$-P2VP sample with a thickness over $45 L_{0}$ annealed in chloroform vapor atmosphere at $27^{\circ} \mathrm{C}$ for a week.

Table 2. Vapor pressure (VP), Hildebrand solubility parameter $(\delta)$, and enthalpy derived interaction parameter $\left(\chi_{\mathrm{H}}^{\infty}\right)$, relative to the individual blocks and the copolymer, for toluene and chloroform at $273.15 \mathrm{~K}$.

\begin{tabular}{ccccc}
\hline Solubility Parameters... & Toluene & Chloroform & PS & P2VP \\
\hline Vapor Pressure $(\mathrm{mm} / \mathrm{Hg})$ & 21.9 & 156.05 & - & - \\
Molar voume $\left(\mathrm{cm}^{3} / \mathrm{mol}\right)$ & 105.7 & 79.5 & - & - \\
$\delta\left(\left(\mathrm{cal} / \mathrm{cm}^{3}\right) 1 / 2\right)^{\mathrm{a}}$ & 18.3 & 18.7 & 18.5 & 20.6 \\
$\chi_{\mathrm{H}}^{\infty}(\mathrm{PS})^{\mathrm{b}}$ & 0.00 & 0.00 & - & - \\
$\chi_{\mathrm{H}}^{\infty}(\mathrm{P} 2 \mathrm{VP})$ & 0.11 & 0.08 & - & - \\
\hline
\end{tabular}

${ }^{a}$ Hildebrand solubility parameter ( $\delta$ ) [31]; ${ }^{b}$ Solvent-polymer interactions can be predicted from the solvent parameter on the basis of complementary matching and an interaction parameter (enthalpy related and at infinite dilution), $\chi_{\mathrm{H}}^{\infty}$ given by $(\mathrm{Vi} / \mathrm{RT})\left(\delta_{\mathrm{i}}-\delta_{\mathrm{j}}\right)^{2}$ where $\mathrm{V}$ is the molar volume and $\mathrm{i}$ and $\mathrm{j}\left(\delta_{\mathrm{i}}\right.$ and $\left.\delta_{\mathrm{j}}\right)$ represent the solubility parameters of the two components [31].

One of the advantages of the spin-coating technique for thin film preparation is that the thickness (d) is controllable, depending on the spin-coating conditions applied, as listed in Table 1 of the experimental section. Silicon (Si) wafers with a native silicon oxide layer on the surface, which are normally considered as preferentially wet P2VP blocks, [32] were used substrates for the spin-coating of the thin film, followed by the SVA processes of as-prepared thin films conducted by enclosing the sample in a temperature-controlled, closed container that contains a small reservoir of liquid solvent. However, the perpendicular orientation, particularly for relatively thick $\mathrm{BCP}$ films, suffers from the parallel orientation if there is preferential segregation of one block at the free surface in respect to the other block [25]. A thickness range of $0.4 L_{0}$ to $0.8 L_{0}$ (i.e., from 60 to $100 \mathrm{~nm}$ ) was specifically studied here in order to avoid multilayer formation on the top of the substrate, in which case phase behaviors can also be easily monitoring monitored by Atomic Force Microscopy (AFM) and Transmission electron microscopy (TEM) during the SVA process.

However, the final morphologies of $\mathrm{BCP}$ thin films are actually the results of a balance between interfacial interactions (with the substrate and free surface) of block components during the SVA processes. When different types of solvents were employed, surface interactions of PS- $b$-P2VP blocks with solvent vapor can be varied and thus are expected to lead to various ordered architectures of $\mathrm{BCP}$ formed [22]. Therefore, the effects of two different types of solvents, i.e., the selective solvent toluene and the less-selective solvent chloroform (Table 2), were particularly studied.

In the presence of the selective solvent vapor, in this case toluene, the PS block of the PS-b-P2VP can be preferentially swollen, which results in a reconstruction of the films. The solvent pressure in a closed system is expected to reach an equilibrium value in a short period of time, and thus prolonging the annealing time can provide sufficient time for PS chain movement at a given temperature. As shown in the AFM height profiles of the 60-nm (thickness $d \approx 0.4 L_{0}$ ) thin film from Figure 2, initial spherical micellar structures were changed into various morphologies with the increase of the annealing time at 
$50{ }^{\circ} \mathrm{C}$. However, only locally ordered structures were formed in the time length scale up to $43 \mathrm{~h}$ because the movements of block copolymers for such thin films were greatly trapped by the interaction between the P2VP block and the oxidized silicon substrate [21,33-35]. Even though cylindrical morphologies perpendicular to the substrate was trapped once during repeated experiments at the annealing time for $5 \mathrm{~h}$, the observed hexagonal ordered array encountered problems when it was attempted to be repeated using the same annealing procedure (Figure 3), probably because the resulting non-equilibrium morphology from the SVA process is a metastable state and sensitive to a range of other parameters including the swelling ratio, as well as swelling and de-swelling rates. No obvious difference in the surface morphology was observed when increasing on the thickness of PS- $b$-P2VP films from 60 to $120 \mathrm{~nm}\left(0.4 L_{0}\right.$ to roughly around $\left.0.8 L_{0}\right)$ (Figure 4$)$ when annealing thin films for $3 \mathrm{~h}$ at $50{ }^{\circ} \mathrm{C}$. With further prolonging the annealing time to $63 \mathrm{~h}$, however, the thicker $80-\mathrm{nm}$ film $\left(0.5 \mathrm{~L}_{0}\right)$ formed more ordered micelle-like structures (Figure 5), suggesting the possibility of achieving even more ordered structures via adjusting the annealing conditions, such as increasing the annealing time or the vapor temperature.

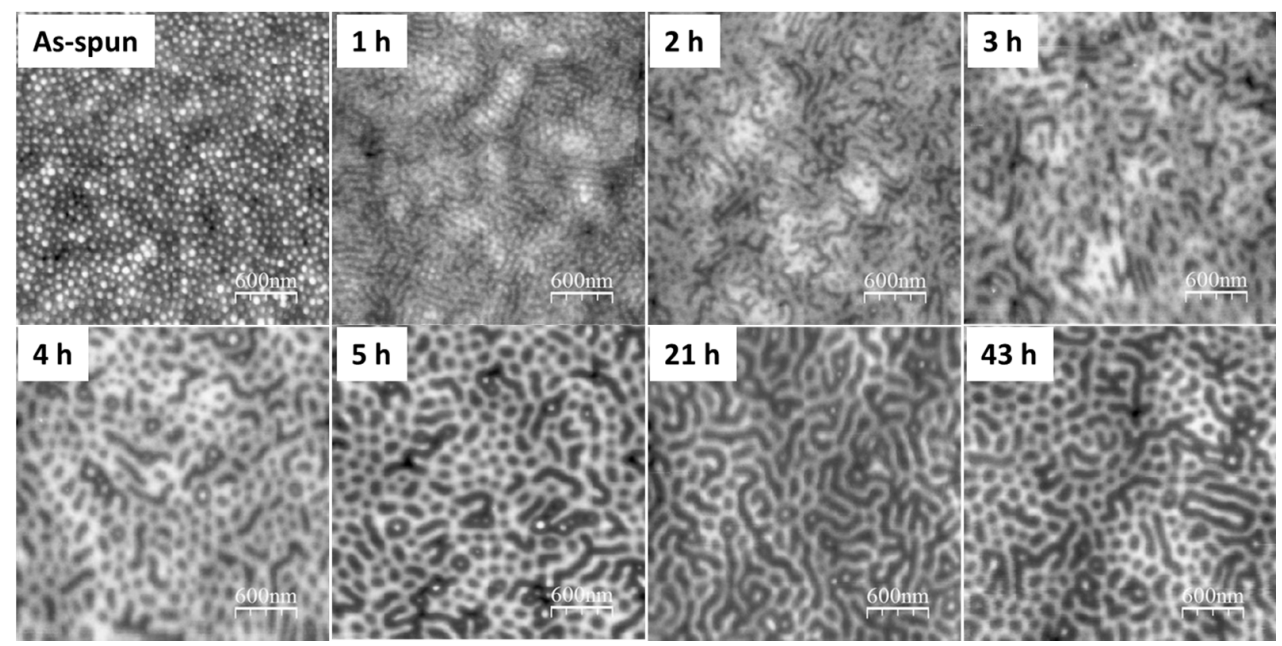

Figure 2. AFM surface height profiles of $60 \mathrm{~nm}$ PS- $b$-P2VP thin films spin-coated at $3000 \mathrm{rpm}$ from $1.5 \mathrm{wt} \%$ solution in toluene with further annealing under toluene vapor atmosphere at $50{ }^{\circ} \mathrm{C}$ with different annealing times.

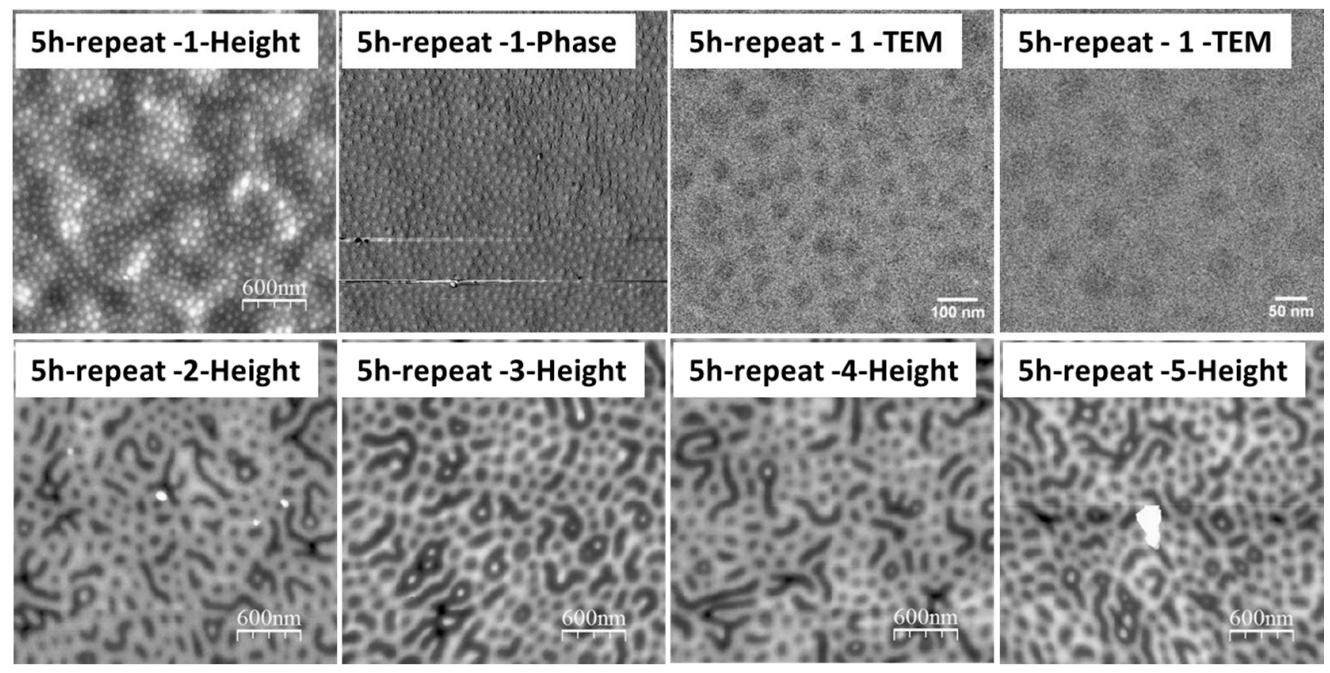

Figure 3. AFM surface profiles and TEM images of the 60-nm PS- $b$-P2VP thin films spin-coated at $3000 \mathrm{rpm}$ from $1.5 \mathrm{wt} \%$ solution in toluene with further annealing under toluene vapor atmosphere at $50{ }^{\circ} \mathrm{C}$ for $5 \mathrm{~h}$ with several repeated experiments. 


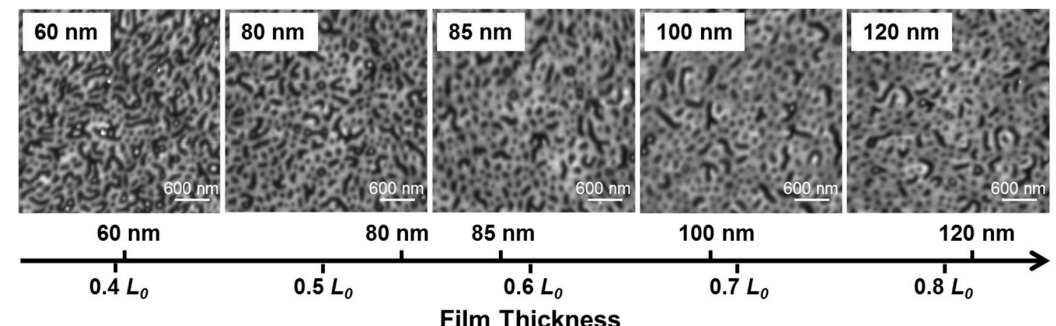

Figure 4. AFM surface height profiles of PS- $b$-P2VP thin films with different thicknesses annealed under toluene vapor atmosphere at $50^{\circ} \mathrm{C}$ for $3 \mathrm{~h}$.

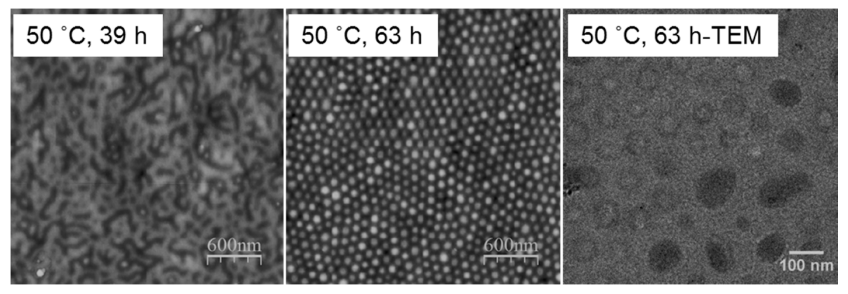

Figure 5. AFM height profiles and TEM images of the 80-nm PS- $b$-P2VP thin films spin-coated at $2500 \mathrm{rpm}$ from $1.5 \mathrm{wt} \%$ solution in toluene with further annealing in toluene vapor atmosphere at $60{ }^{\circ} \mathrm{C}$ with different annealing times.

High temperature can give rise to better diffusivity of the highly entangled polymer chains, which would greatly decrease the annealing time length scale. As displayed in surface AFM images and cross-sectional TEM images of obtained thin film structures in Figure 6, obvious phase transition of PS- $b$-P2VP films with a pathway of micelles-perpendicular cylinders $(\sim 45 \mathrm{~nm})$-micelles-parallel cylinders was demonstrated. Specifically, highly ordered micelle-like structures with the micelle size around $100 \mathrm{~nm}$ were formed at $60^{\circ} \mathrm{C}, 72 \mathrm{~h}$ among these annealing processes. The state became less ordered at annealing times above $72 \mathrm{~h}$, such as at $96 \mathrm{~h}$. In principle, both vapor pressure and thermal chain mobility can be increased by increasing the temperature from $60^{\circ} \mathrm{C}$ to a higher temperature, and thus ordered structures can be expected in a shorter time. However, further increasing the annealing temperature did not improve the ordering degree of films, as normally occurs [36]. On the contrary, thin films were separated into thinner and thicker regions at higher annealing temperatures like 70 or $80^{\circ} \mathrm{C}$ (Figure 7), an effect known as terraces formation [37-40], due to the obvious change in the surface energy and thus the overall morphology at high temperature region. Meanwhile, the microstructure at the slope between the islands of different thicknesses was still lamellar at the temperature of $80^{\circ} \mathrm{C}$.

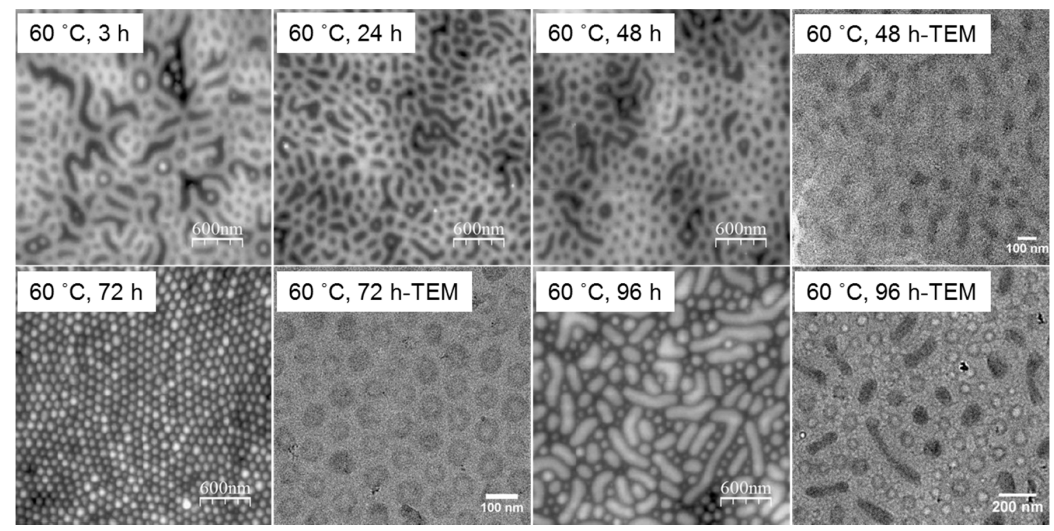

Figure 6. AFM height profiles and TEM images of the 80-nm PS- $b$-P2VP thin films spin-coated at $2500 \mathrm{rpm}$ from $1.5 \mathrm{wt} \%$ solution in toluene with further annealing in toluene vapor atmosphere at $60^{\circ} \mathrm{C}$. 


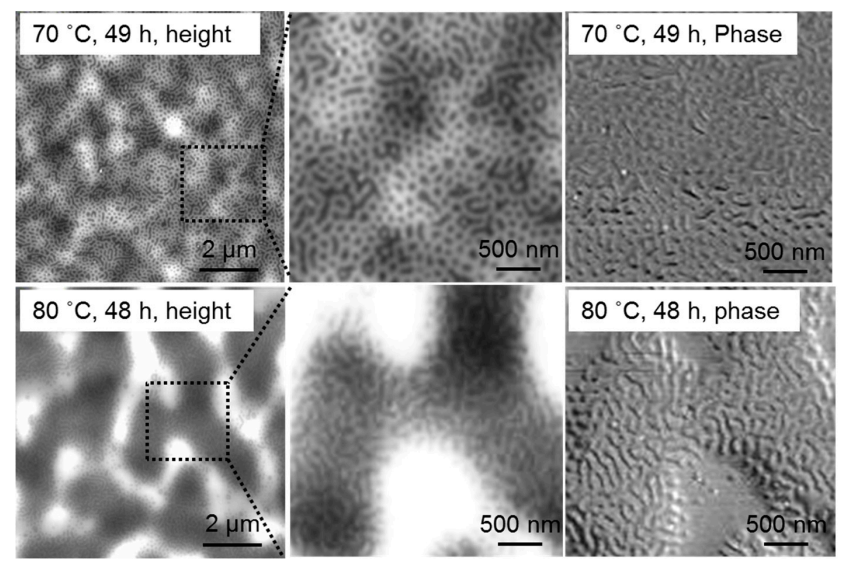

Figure 7. AFM profiles and TEM images of the 80-nm PS- $b$-P2VP thin films spin-coated at $2500 \mathrm{rpm}$ from $1.5 \mathrm{wt} \%$ solution in toluene with further annealing in toluene vapor atmosphere at $70{ }^{\circ} \mathrm{C}$ and $80{ }^{\circ} \mathrm{C}$.

Accordingly, to further increase the order degree of perpendicular structures, the interaction of PS- $b$-P2VP blocks with free surfaces have to be greatly increased to thus neutralize the substrate interaction. Chloroform, a less selective solvent for PS-b-P2VP along with higher vapor pressure as compared to toluene (Table 2), is thus further used as the vapor solvent, in which case much higher chain mobility can also be expected. The AFM images in Figure 8 demonstrate that ordered structures with fingerprint-like lamellar surface morphologies were formed in quite short annealing periods for all films with thicknesses from 60 to $100 \mathrm{~nm}$. Similar to the toluene system, the longer the annealing time applied, the higher the degree of phase separation achieved. Generally, a thinner film takes a shorter time to form ordered structures. The cross-sectional TEM images of 80- and 100-nm thick PS- $b$-P2VP films confirmed the one-layer structures perpendicular to the substrate, indicating a balance between the free surface and substrate interaction for PS- $b$-P2VP in the presence of chloroform at the given conditions. For the same reasons, P2VP chains from the substrate interface and PS segments from the free surface move into the BCP phases, respectively, contributing to the increase of the domain sizes for thicker films at the same annealing conditions.

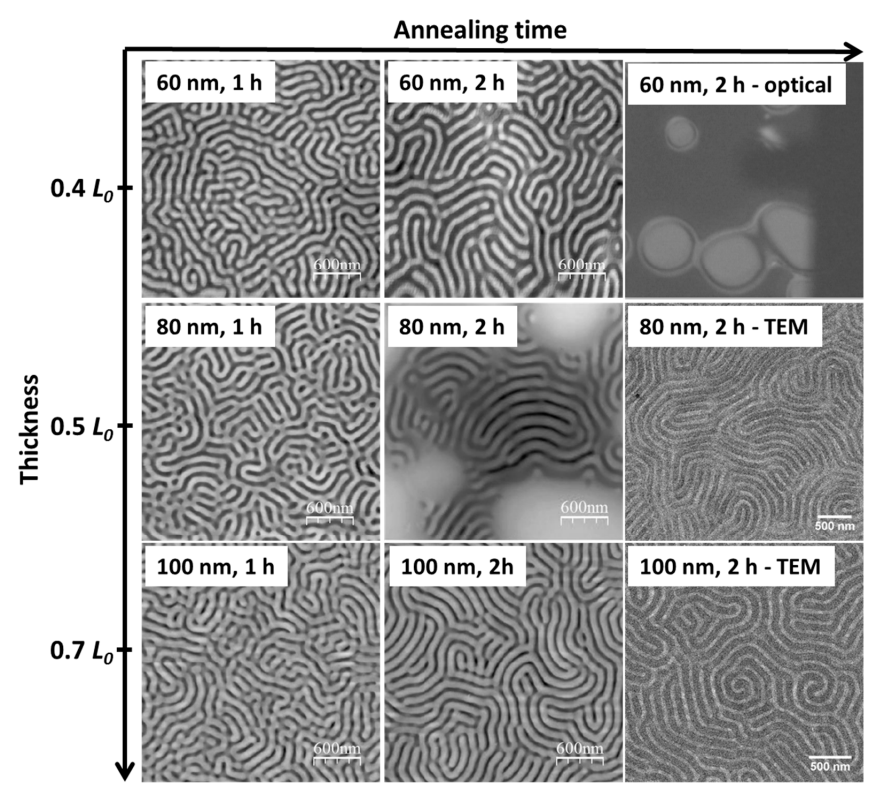

Figure 8. AFM surface height profiles, optical microscope image (upper-right corner), and TEM images of the PS- $b$-P2VP thin films annealed in chloroform vapor atmosphere at $27^{\circ} \mathrm{C}$ for different time periods. 
It should be mentioned that the thickness of the film must be carefully considered because much thinner films can be easy to dewet, especially if the films were exposed to a solvent atmosphere with high vapor pressure, such as a chloroform atmosphere. For example, ring-like micron-sized defects (white circular regions in the upper-right image of Figure 8) were formed for 60-nm thick films $\left(d \approx 0.4 L_{0}\right)$ when they were annealed just for $2 \mathrm{~h}$. Even though the microstructures are fingerprint-like lamellar in the major dark region, structures other than perpendicular lamellar structures were found (Figure 9) within the defect and also in the slope of these defects. Also, extra layers were observed for 80 -nm films $\left(d \approx 0.5 L_{0}\right)$ (Figure 9$)$ annealed for $2 \mathrm{~h}$. The formation of terraces (i.e., islands or holes) in these two samples actually depends on the interaction of the blocks with the substrate and the vapor [21]. In particular, when the thickness of a film is incompatible with this inherent length scale, non-favorable interactions of the solvent with the substrate could result in terraces. The phenomena can be avoided by further increasing the film thickness to $100 \mathrm{~nm}$, suggesting a synergistic effect between the film thickness and the annealing time.

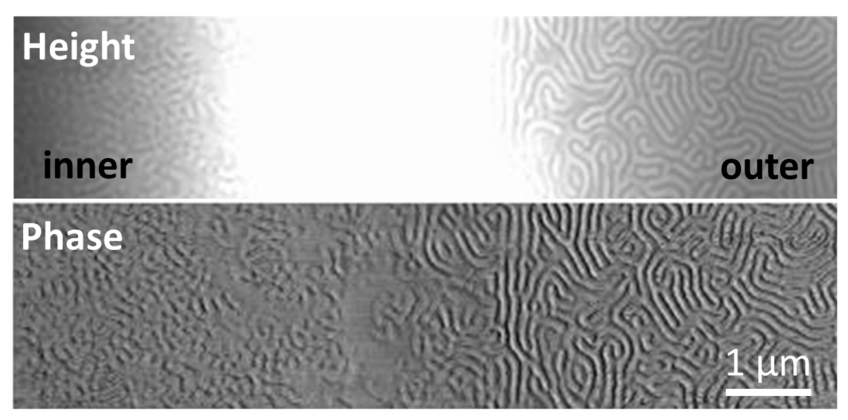

Figure 9. AFM surface height and phase profile (aspect ratio was 1:8) for the edge region of the defect ring from the 60-nm PS- $b$-P2VP thin films annealed under chloroform vapor atmosphere at $27^{\circ} \mathrm{C}$ for $120 \mathrm{~min}$.

\section{Conclusions}

Phase behaviors of PS- $b$-P2VP thin films with thicknesses ranging from $0.4 L_{0}$ up to $0.8 L_{0}$ were investigated. In these cases, perpendicular structures in regard to the substrate were normally formed, which were found to be very sensitive to the solvent vapors. A strong selective solvent, such as toluene for PS-b-P2VP, can preferentially swell one block (PS) and thus change the effective block "composition" and possibly also the "equilibrium" state of the BCP (forming cylinders and micelles rather than a lamellar morphology) during the slow phase transition process. In contrast to this, a less selective solvent vapor, such as chloroform vapor for PS- $b$-P2VP, can balance the interactions of the free surface and substrate of these two blocks, and thus result in morphologies close to the bulk equilibrium state (fingerprint-like lamellar morphologies in our case) in quite short annealing periods. Terraces were formed in thinner films as compared to thicker ones at given time length scales, particularly in a thickness range below the inherent length scale of the BCP (i.e., $d<L_{0}$ ). One of the main merits of our work is that the phase behavior of the ultra-high molecular weight BCP thin films, which hold above 100-nm sized domain distances, can be easily monitored via current available techniques, such as SEM, AFM, and TEM, which are expected to provide experimental guidelines for the optimization of treatment conditions during the SVA processes of other BCPs.

Acknowledgments: We appreciate the funding from the Netherlands Organization for Scientific Research (NWO) and the China Scholarship Council.

Author Contributions: Qiuyan Yang and Katja Loos conceived and designed the experiments; Qiuyan Yang performed the experiments; Qiuyan Yang and Katja Loos analyzed the data; Katja Loos contributed reagents/materials/analysis tools; Qiuyan Yang and Katja Loos wrote the paper.

Conflicts of Interest: The authors declare no conflict of interest. 


\section{References}

1. Hu, H.Q.; Gopinadhan, M.; Osuji, C.O. Directed self-assembly of block copolymers: A tutorial review of strategies for enabling nanotechnology with soft matter. Soft Matter 2014, 10, 3867-3889. [CrossRef] [PubMed]

2. Albert, J.N.L.; Epps, T.H., III. Self-assembly of block copolymer thin films. Mater. Today 2010, 13, $24-33$. [CrossRef]

3. Van Zoelen, W.; ten Brinke, G. Thin films of complexed block copolymers. Soft Matter 2009, 5, 1568-1582. [CrossRef]

4. Sinturel, C.; Vayer, M.; Morris, M.; Hillmyer, M.A. Solvent vapor annealing of block polymer thin films. Macromolecules 2013, 46, 5399-5415. [CrossRef]

5. Park, S.; Wang, J.-Y.; Kim, B.; Xu, J.; Russell, T.P. A simple route to highly oriented and ordered nanoporous block copolymer templates. ACS Nano 2008, 2, 766-772. [CrossRef] [PubMed]

6. Park, S.; Kim, B.; Wang, J.-Y.; Russell, T.P. Fabrication of highly ordered silicon oxide dots and stripes from block copolymer thin films. Adv. Mater. 2008, 20, 681-685. [CrossRef]

7. Park, S.; Wang, J.-Y.; Kim, B.; Russell, T.P. From nanorings to nanodots by patterning with block copolymers. Nano. Lett. 2008, 8, 1667-1672. [CrossRef] [PubMed]

8. Park, S.; Kim, B.; Cirpan, A.; Russell, T.P. Preparation of metallic line patterns from functional block copolymers. Small 2009, 5, 1343-1348. [CrossRef] [PubMed]

9. Park, S.; Kim, B.; Yavuzcetin, O.; Tuominen, M.T.; Russell, T.P. Ordering of PS- $b$-P4VP on patterned silicon surfaces. ACS Nano 2008, 2, 1363-1370. [CrossRef] [PubMed]

10. Park, S.; Lee, D.H.; Xu, J.; Kim, B.; Hong, S.W.; Jeong, U.; Xu, T.; Russell, T.P. Macroscopic 10-terabit-persquare-inch arrays from block copolymers with lateral order. Science 2009, 323, 1030-1033. [CrossRef] [PubMed]

11. Park, S.; Lee, D.H.; Russell, T.P. Self-assembly of block copolymers on flexible substrates. Adv. Mater. 2010, 22, 1882-1884. [CrossRef] [PubMed]

12. Gotrik, K.W.; Hannon, A.F.; Son, J.G.; Keller, B.; Alexander-Katz, A.; Ross, C.A. Morphology control in block copolymer films using mixed solvent vapors. ACS Nano 2012, 6, 8052-8059. [CrossRef] [PubMed]

13. Chavis, M.A.; Smilgies, D.-M.; Wiesner, U.B.; Ober, C.K. Widely tunable morphologies in block copolymer thin films through solvent vapor annealing using mixtures of selective solvents. Adv. Funct. Mater. 2015, 25, 3057-3065. [CrossRef] [PubMed]

14. Paradiso, S.P.; Delaney, K.T.; García-Cervera, C.J.; Ceniceros, H.D.; Fredrickson, G.H. Block dopolymer delf-assembly during rapid solvent evaporation: insights into cylinder growth and stability. ACS Macro. Lett. 2014, 3, 16-20. [CrossRef]

15. Albert, J.N.L.; Young, W.-S.; Lewis, R.L., III; Bogart, T.D.; Smith, J.R.; Epps, T.H., III. Systematic study on the effect of solvent removal rate on the morphology of solvent vapor annealed ABA triblock copolymer thin films. ACS Nano 2012, 6, 459-466. [CrossRef] [PubMed]

16. Wu, Y.-H.; Lo, T.-Y.; She, M.-S.; Ho, R.-M. Morphological evolution of gyroid-forming block copolymer thin films with varying solvent evaporation rate. ACS Appl. Mater. Interfaces 2015, 7, 16536-16547. [CrossRef] [PubMed]

17. Gu, X.D.; Gunkel, I.; Hexemer, A.; Gu, W.Y.; Russell, T.P. An in situ grazing incidence X-ray scattering study of block copolymer thin films during solvent vapor annealing. Adv. Mater. 2014, 26, 273-281. [CrossRef] [PubMed]

18. Park, W.I.; Kim, J.M.; Jeong, J.W.; Jung, Y.S. Deep-nanoscale pattern engineering by immersion-induced self-assembly. ACS Nano 2015, 8, 10009-10018. [CrossRef] [PubMed]

19. Park, W.I.; Kim, K.; Jang, H.-I.; Jeong, J.W.; Kim, J.M.; Choi, J.; Park, J.H.; Jung, Y.S. Directed self-sssembly with sub-100 degrees celsius processing temperature, sub-10 nanometer resolution, and sub-1 minute assembly time. Small 2012, 8, 3762-3768. [CrossRef] [PubMed]

20. Jung, J.; Park, H.-W.; Lee, S.; Lee, H.; Chang, T.; Matsunaga, K.; Jinnai, H. Effect of film thickness on the phase behaviors of diblock copolymer thin film. ACS Nano 2010, 4, 3109-3116. [CrossRef] [PubMed]

21. Olszowka, V.; Tsarkova, L.; Boker, A. 3-dimensional control over lamella orientation and order in thick block copolymer films. Soft Matter 2009, 5, 812-819. [CrossRef] 
22. Van Zoelen, W.; Asumaa, T.; Ruokolainen, J.; Ikkala, O.; ten Brinke, G. Phase behavior of solvent vapor annealed thin films of PS- $b$-P4VP(PDP) supramolecules. Macromolecules 2008, 41, 3199-3208. [CrossRef]

23. Shamsudin, S.A.B.; Sakaguchi, G.; Takenaka, M.; Hasegawa, H. Influence of temperature and type of solvents on the microdomain orientation of PS-b-P2VP ultrathin films by solvent annealing. Macromol. Symp. 2013, 327, 72-79. [CrossRef]

24. O'Driscoll, S.; Demirel, G.; Farrell, R.A.; Fitzgerald, T.G.; O'Mahony, C.; Holmes, J.D.; Morris, M.A. The morphology and structure of PS- $b$-P4VP block copolymer films by solvent annealing: effect of the solvent parameter. Polym. Adv. Technol. 2009, 22, 915-923. [CrossRef]

25. Suh, H.S.; Kang, H.; Nealey, P.F.; Char, K. Thickness eependence of neutral parameter windows for perpendicularly oriented block copolymer thin films. Macromolecules 2010, 43, 4744-4751. [CrossRef]

26. Cheng, L.-C.; Bai, W.B.; Martin, E.F.; Tu, K.-H.; Ntetsikas, K.; Liontos, G.; Avgeropoulos, A.; Ross, C.A. Morphology, directed self-assembly and pattern transfer from a high molecular weight polystyrene-blockpoly(dimethylsiloxane) block copolymer film. Nanotechnology 2017, 28, 145301. [CrossRef] [PubMed]

27. Wang, X.; Davis, J.L.; Hinestrosa, J.P.; Mays, J.W.; Kilbey, S.M., II. Control of self-assembled structure through architecturally and compositionally complex block copolymer surfactant mixtures. Macromolecules 2014, 47, 7138-7150. [CrossRef]

28. Glass, R.; Möller, M.; Spatz, J.P. Block copolymer micelle nanolithography. Nanotechnology 2003, 14, 1153-1160. [CrossRef]

29. Jeon, S.-M.; Lee, S.H.; Yoo, S.I.; Sohn, B.-H. Ordered complex nanostructures from bimodal self-assemblies of diblock copolymer micelles with solvent annealing. Langmuir 2011, 27, 12191-12196. [CrossRef] [PubMed]

30. Lin, Y.; Böker, A.; He, J.B.; Sill, K.; Xiang, H.Q.; Abetz, C.; Li, X.F.; Wang, J.; Emrick, T.; Long, S.; et al. Self-directed self-assembly of nanoparticle/copolymer mixtures. Nature 2005, 434, 55-59. [CrossRef] [PubMed]

31. Barton, A.F.M. CRC Handbook of Polymer-Liquid Interaction Parameters and Solubility Parameters; CRC Press: Boca Raton, FL, USA, 1990.

32. Spatz, J.P.; Sheiko, S.; Möller, M. Substrate-induced lateral micro-phase separation of a diblock copolymer. Adv. Mater. 1996, 8, 513-517. [CrossRef]

33. Fasolka, M.J.; Mayes, A.M. Block copolymer thin films: Physics and applications. Annu. Rev. Mater. Res. 2001, 31, 323-355. [CrossRef]

34. Zhao, J.C.; Jiang, S.C.; Ji, X.L.; An, L.J.; Jiang, B.Z. Study of the time evolution of the surface morphology of thin asymmetric diblock copolymer films under solvent vapor. Polymer 2005, 46, 6513-6521. [CrossRef]

35. Li, X.; Peng, J.; Wen, Y.; Kim, D.H.; Knoll, W. Morphology change of asymmetric diblock copolymer micellar films during solvent annealing. Polymer 2007, 48, 2434-2443. [CrossRef]

36. Huang, H.; Hu, Z.; Chen, Y.; Zhang, F.; Gong, Y.; He, T. Effects of casting solvents on the formation of inverted phase in block copolymer thin films. Macromolecules 2004, 37, 6523-6530. [CrossRef]

37. Kim, B.K.; Hong, S.W.; Park, S.; Xu, J.; Hong, S.-K.; Russell, T.P. Phase transition behavior in thin films of block copolymers by use of immiscible solvent vapors. Soft Matter 2011, 7, 443-447. [CrossRef]

38. Epps, T.H., III; De Longchamp, D.M.; Fasolka, M.J.; Fischer, D.A.; Jablonski, E.L. Substrate surface energy dependent morphology and dewetting in an ABC triblock copolymer film. Langmuir 2007, 23, 3355-3362. [CrossRef] [PubMed]

39. Peng, J.; Xuan, Y.; Wang, H.F.; Li, B.Y.; Han, Y.C. Solvent vapor induced dewetting in diblock copolymer thin films. Polymer 2005, 46, 5767-5772. [CrossRef]

40. Lyakhova, K.S.; Horvat, A.; Zvelindovsky, A.V.; Sevink, G.J.A. Dynamics of terrace formation in a nanostructured thin block copolymer film. Langmuir 2006, 22, 5848-5855. [CrossRef] [PubMed]

(C) 2017 by the authors. Licensee MDPI, Basel, Switzerland. This article is an open access article distributed under the terms and conditions of the Creative Commons Attribution (CC BY) license (http:/ / creativecommons.org/licenses/by/4.0/). 